\title{
Visual outcomes and prognostic factors in open-globe injuries
}

\author{
Azusa Fujikawa', Yasser Helmy Mohamed ${ }^{12^{*}}$ (D), Hirofumi Kinoshita', Makiko Matsumoto', Masafumi Uematsu',
} Eiko Tsuiki ${ }^{1}$, Kiyoshi Suzuma ${ }^{3}$ and Takashi Kitaoka ${ }^{1}$

\begin{abstract}
Background: Ocular trauma is an important cause of visual loss worldwide. Improvements in our knowledge of the pathophysiology and management of ocular trauma during the past 30 years, in conjunction with advances in the instrumentation and techniques of ocular surgery, have improved the efficacy of vitreoretinal surgery in injured eyes. The aim of the current study was to determine the visual outcomes and prognostic factors of open-globe injuries in the Japanese population.
\end{abstract}

Methods: Retrospective study of 59 eyes of 59 patients presented with open globe injuries between September 2008 and March 2014 at Nagasaki University Hospital was conducted.

Demographic factors including age, gender, and clinical data such as cause of injury, presenting visual acuity (VA), location of injury, type of injury, lens status, presence of intraocular foreign body, types of required surgeries, and final VA were recorded. According to the classification of Ocular Trauma Classification Group, wound location was classified into three zones. Chi-square test was used to compare presented data.

Results: Out of the 59 patients, 46 were placed in the Light Perception (LP) group, and 13 were placed in the No Light Perception (NLP) group. Work-related trauma was the most common cause (27 eyes) followed by falls (19eyes). Work-related trauma was common in males $(P=0.004)$, while falls was significantly common in females $(P=0.00001)$. Zone III injuries had statistically significantly poor prognostic factor compared to other zones $(P=0.04)$. All cases of NLP group (100\%) presented with rupture globe. Poor VA at first visit $(P=0.00001)$, rupture globe $(P=0.026)$, history of penetrating keratoplasty $(P K)(P=0.017)$, retinal detachment $(R D)(P=0.0001)$, vitreous hemorrhage $(\mathrm{VH})(P=0.044)$, and dislocation of crystalline lens $(P=0.0003)$ were considered as poor prognostic factors.

Conclusion: Poor VA at first visit, rupture globe, zone III injuries, history of penetrating keratoplasty, RD, VH, and dislocation of crystalline lens were found to be poor prognostic factors. PPV had a good prognostic value in open globe injuries associated with posterior segment involvement.

Keywords: Open-globe injury, Vitrectomy, Retinal detachment, Penetrating keratoplasty

\section{Background}

Ocular trauma is a prominent cause of visual disability and, depending on the sample population, can contribute up to $65 \%$ of the cases of unilateral blindness worldwide. The burden of blindness is related to both its inevitable effect on the quality of life and the loss of

\footnotetext{
*Correspondence: yasserhelmy@nagasaki-u.ac.jp

'Department of Ophthalmology and Visual Sciences, Graduate School of Biomedical Sciences, Nagasaki University, 1-7-1 Sakamoto, Nagasaki, Nagasaki 852-8501, Japan

${ }^{2}$ Department of Ophthalmology, EL-Minia University Hospital, EL-Minia, Egypt Full list of author information is available at the end of the article
}

productivity that subsequently occurs in these subjects $[1,2]$. Mechanical trauma to the eye has been classified by the Birmingham Eye Trauma Terminology (BETT) and Ocular Trauma Classification Group and subdivided it into open and closed globe injuries [3].

An open-globe injury is defined as a full thickness wound of the eye wall (full injury of the sclera, cornea, or both) with this vision-threatening condition often leading to blindness. Although there has been considerable effort to prevent this type of blindness, it remains common around the world, with an annual global

(c) The Author(s). 2018 Open Access This article is distributed under the terms of the Creative Commons Attribution 4.0 International License (http://creativecommons.org/licenses/by/4.0/), which permits unrestricted use, distribution, and 
incidence rate of $3.5 / 100,000$ persons [4]. There is worldwide interest in the epidemiology of ocular trauma [2]. Different studies have reported varying proportions of open versus closed globe injury [5-7]. Although public health campaigns have been organized to prevent eye injuries, unfortunately, open-globe injuries are still too frequent. Moreover, it has been shown that open-globe injuries result in more hospitalization and a poorer visual outcome compared to closed globe injuries $[8,9]$.

Improvements in our knowledge of the pathophysiology and management of ocular trauma during the past 30 years, in conjunction with advances in the instrumentation and ocular surgery techniques, have improved the efficacy of vitreoretinal surgery in injured eyes [10].

Achieving or maintaining useful vision is dependent upon several prognostic factors, such as the severity of the initial trauma, involvement of ocular structures, preoperative visual acuity, and both a timely diagnosis and treatment $[10,11]$.

The aim of the current study was to determine the visual outcomes and prognostic factors of open-globe injuries in the Japanese population.

\section{Methods}

This retrospective study reviewed the records of all subjects who sustained an open-globe injury and were examined at Nagasaki University Hospital between September 2008 and March 2014.

Reviews of the patients' medical charts included the initial ophthalmology consultation notes, hospital records, details of the primary and subsequent surgical interventions, and outpatient follow-up records. During the review of the records, demographics, including age and gender, wound characteristics (i.e., mechanism, causes, sizes, and locations), and visual acuity (VA) (presenting and final VA), were collected. The final VA was defined as the VA at the end of the follow-up. Associated ocular damage (i.e., vitreous hemorrhage $(\mathrm{VH})$, retinal detachment (RD), intraocular foreign body (IOFB), lens status, and endophthalmitis) was also evaluated.

Based on the Birmingham Eye Trauma Terminology, the mechanisms of injury were classified as rupture, penetration, IOFB, perforation, and mixed injury [3]. In cases in which there was a high clinical suspicion of an IOFB that could not be confirmed by clinical examination or in which the media opacity prohibited any examination of intraocular structures, ancillary testing with X-rays, computed tomography, or echography were used to classify the injuries.

Patients were divided into groups according to the real size of the wound (in $\mathrm{mm}$ ). The 4 classifications used included wounds that were smaller than $5 \mathrm{~mm}, 5-10 \mathrm{~mm}$, 10-15 $\mathrm{mm}$, and larger than $15 \mathrm{~mm}$.

Distance VA was tested using a Landolt $C$ acuity chart. If the VA improved when using a pinhole, this was recorded as the VA at the initial examination. Details of the primary and subsequent treatments and final VAs were also collected. The initial VA was divided into the following 6 categories: acuity 20/40 or better, between 20/40 to $20 / 400$, between $20 / 400$ to counting fingers (CF), hand movement (HM), light perception (LP), and no light perception (NLP). The outcome, which was defined as the VA measured at the last visit, was divided into 2 categories: ocular survival (with VA ranging between 20/20 and LP) (LP group) and NLP (NLP group). The visual acuity of NLP was confirmed using a bright light source, such as an indirect ophthalmoscope. This light source was set at the highest intensity during which time the fellow eye was completely occluded. A cross-sectional analysis was performed on all patient data in order to investigate the correlation between the initial and final VA. As part of this investigation, we used a value of $1 / 400 \mathrm{VA}(\operatorname{logMAR}=2.6)$ to represent the vision of the CF patients, with the extrapolated values of $2.7,2.8$, and $2.9 \operatorname{logMAR}$ used to represent HM, LP, and NLP, respectively.

Wound locations were classified according to the Ocular Trauma Classification Group [3]. Zone I injuries were confined to the cornea and limbus, zone II injuries involved the anterior $5 \mathrm{~mm}$ from the limbus (not extending into the retina), and zone III injuries extended to the posterior by more than $5 \mathrm{~mm}$ from the limbus. In cases of multiple corneoscleral openings, the zone was defined according to the most posterior opening. In cases of IOFBs, the zone was defined at the specific entry site. For perforating injuries, however, the zone was defined by the most posterior defect, which was generally the exit site. While all of the zones of the injury were determined at the time of the initial examination, in some cases, the exact extent of the injury was more accurately determined during the surgical intervention, which led to further identification and revision of the zone of injury.

After collecting all of the records, the data were evaluated for the influences of the initial VA, wound location and size, mechanism of injury, and associated ocular tissue damage on the visual survival rates. This study was approved by the Institutional Review Board (IRB) of the Nagasaki University Hospital and adhered to the tenets of the Declaration of Helsinki.

Statistical Methods:

A Student's two-tailed t-test was used to compare the quantitative variables, while the chi-square test was used to compare the categorical data. Values of $p<0.05$ were considered statistically significant.

\section{Results}

\section{Patient demographics}

This study evaluated 59 patients (46 in the LP group and 13 in the NLP group). The mean age was $56.7 \pm 21.8$ years in the LP group and $62.3 \pm 21.7$ years in the NLP group, with no significant difference found between the two groups $(p=0.21)$. Figure 1 presents the details for the age 


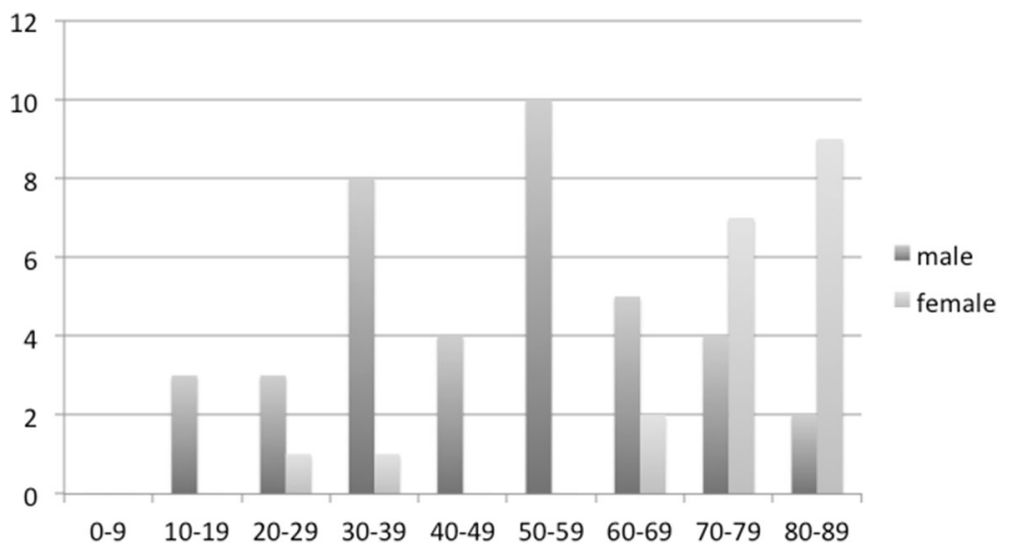

Fig. 1 Sex and age distribution of the patients with open-globe injury. The patient group consisted of 39 (66.1\%) males and 20 (33.9\%) females, with a male:female ratio of nearly 2:1

and gender distribution. Only 1 case was younger than the age of 16 years. The patient group included 39 (66.1\%) males and $20(33.9 \%)$ females, resulting in a ratio of nearly 2:1.

None of the patients presented with a bilateral open-globe injury. The injuries occurred in 27 right eyes and in 32 left eyes, with no significant difference with regard to the side.

\section{Cause of injury}

Work-related trauma (27 [45.8\%] eyes) was the most common cause of the injury, which was followed by falls (19 [32.2\%] eyes). Work-related trauma was common in males $(p=0.004)$, while falls were common in females $(p=0.00001)$ (Fig. 2). The mean ages were $51.3 \pm 18.1$ years for the work-related trauma and $61.1 \pm 8.8$ years for the falls. There were 6 (10.2\%) eye injuries related to sports injuries, and 2 (3.4\%) eye injuries caused by car accidents.

\section{Mechanism of injury}

All 13 (100\%) eyes in the NLP group and 28 (60.8\%) eyes in the LP group presented with a ruptured globe.
Ruptured globe was a statistically significant poor prognostic factor $(p=0.026)$ (Table 1$)$.

Posterior segment IOFBs were observed in 12 (20.3\%) eyes, with all of these patients belonging to the LP group (26.1\%). A metallic IOFB was found in 11 cases, while 1 case had a concrete IOFB. In these patients, IOFB removal was the primary procedure performed, with 3 IOFBs located in the anterior chamber, 2 in the vitreous cavity, 6 in the peripheral retina, and 1 nasal relative to the optic disc in the posterior pole of the eye. IOFB removal was successful in all cases.

Penetrating trauma occurred in the remaining 6 eyes of the LP group (13.1\%). However, neither penetrating trauma nor IOFB exhibited any significant predictive factors.

\section{Location of injury}

Zone III injuries were more common in the eyes with a final VA of NLP (4 [30.8\%] of 13 eyes) as compared to eyes with a final VA of LP or better (4 [8.7\%] of 46 eyes). Zone III injuries were found to be a statistically significant poor prognostic factor for visual outcome

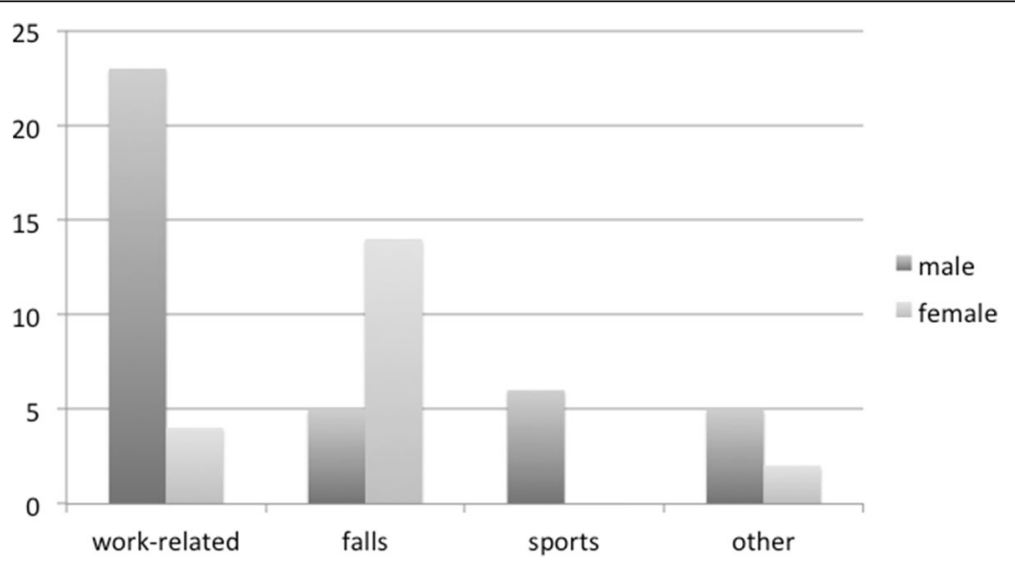

Fig. 2 Cause of injury: Work-related trauma was more common in males $(p=0.004)$, while falls were more common in females $(p=0.00001)$ 
Table 1 Final visual outcomes and prognostic factors

\begin{tabular}{|c|c|c|c|c|}
\hline Final VA & LP & NLP & Total & $P$ value \\
\hline$n$ & 46 & 13 & 59 & \\
\hline Age & 56.7 & 62.3 & & 0.21 \\
\hline \multicolumn{5}{|l|}{ Sex } \\
\hline Male & 30 & 9 & 39 & \multirow[t]{2}{*}{0.67} \\
\hline Female & 16 & 4 & 20 & \\
\hline \multicolumn{5}{|l|}{ Trauma eye } \\
\hline Right & 23 & 4 & 27 & \multirow[t]{2}{*}{0.22} \\
\hline Left & 23 & 9 & 32 & \\
\hline \multicolumn{5}{|l|}{ Type of injury } \\
\hline Penetrating & 6 & 0 & 6 & \multirow[t]{3}{*}{0.026} \\
\hline Rupture & 28 & 13 & 41 & \\
\hline Foreign body & 12 & 0 & 12 & \\
\hline \multicolumn{5}{|l|}{ Location } \\
\hline Zone I & 21 & 4 & 25 & 0.34 \\
\hline Zone II & 21 & 5 & 26 & 0.64 \\
\hline Zone III & 4 & 4 & 8 & 0.04 \\
\hline \multicolumn{5}{|l|}{ Initial Visual Acuity } \\
\hline $20 / 40 \leq$ & 5 & 0 & 5 & \multirow[t]{6}{*}{0.0001} \\
\hline $20 / 400<20 / 40$ & 3 & 0 & 3 & \\
\hline$C F<20 / 400$ & 5 & 0 & 5 & \\
\hline HM & 12 & 0 & 12 & \\
\hline$L P$ & 20 & 5 & 25 & \\
\hline NLP & 1 & 8 & 9 & \\
\hline \multicolumn{5}{|l|}{ Size of injury } \\
\hline$\leq 5 \mathrm{~mm}$ & 17 & 0 & 17 & \multirow[t]{4}{*}{0.0078} \\
\hline 5-10 mm & 21 & 6 & 27 & \\
\hline $10-15 \mathrm{~mm}$ & 8 & 6 & 14 & \\
\hline $15<\mathrm{mm}$ & 0 & 1 & 1 & \\
\hline \multicolumn{5}{|l|}{ Status of the lens } \\
\hline Aphakia & 2 & 2 & 4 & \multirow[t]{3}{*}{0.34} \\
\hline Phakia & 31 & 7 & 38 & \\
\hline Pseudophakia & 13 & 4 & 17 & \\
\hline \multicolumn{5}{|c|}{ Dislocation of the lens } \\
\hline Yes & 5 & 6 & 11 & \multirow[t]{2}{*}{0.00025} \\
\hline No & 26 & 1 & 27 & \\
\hline \multicolumn{5}{|l|}{ History of PKP } \\
\hline Yes & 3 & 4 & 7 & \multirow[t]{2}{*}{0.017} \\
\hline No & 43 & 9 & 52 & \\
\hline \multicolumn{5}{|c|}{ Retinal detachment } \\
\hline Yes & 10 & 10 & 20 & \multirow[t]{3}{*}{0.0001} \\
\hline No & 36 & 1 & 37 & \\
\hline Unknown & 0 & 2 & 2 & \\
\hline
\end{tabular}

Table 1 Final visual outcomes and prognostic factors (Continued)

\begin{tabular}{|c|c|c|c|c|}
\hline Final VA & $L P$ & NLP & Total & $P$ value \\
\hline \multicolumn{5}{|c|}{ Vitreous Hemorrhage } \\
\hline Yes & 27 & 10 & 37 & \multirow[t]{3}{*}{0.0443} \\
\hline No & 19 & 1 & 20 & \\
\hline Unknown & 0 & 2 & 2 & \\
\hline \multicolumn{5}{|c|}{ Primary operation with PPV } \\
\hline Yes & 26 & 3 & 29 & \multirow[t]{2}{*}{0.033} \\
\hline No & 20 & 10 & 30 & \\
\hline \multicolumn{5}{|c|}{$\begin{array}{l}\text { All } 13(100 \%) \text { eyes in the NLP group and } 28(60.8 \%) \text { eyes in the LP group } \\
\text { presented with a ruptured globe. Ruptured globe was a statistically significant } \\
\text { poor prognostic factor }(\mathrm{p}=0.026) \\
V A \text { Visual acuity, } L P \text { Light perception, NLP No light perception, CF counting } \\
\text { fingers, HM hand movement, PK Penetrating Keratoplasty, RD Retinal } \\
\text { detachment, VH Vitreous hemorrhage, PPV Pars plana vitrectomy }\end{array}$} \\
\hline
\end{tabular}

$(p=0.04)$. Zone I injuries were found in $25(42.4 \%)$ eyes (21 in the LP group and 4 in the NPL group), while zone II injuries occurred in $26(44.1 \%)$ eyes (21 in the LP group and 5 in the NPL group). There were no statistically significant predictive factors for visual outcomes found for zones I and II.

\section{Size of the injury}

Patients with a wound that was smaller than $5 \mathrm{~mm}$ had a statistically significant better prognosis than patients with wounds that were larger than $5 \mathrm{~mm}(p=0.0078)$.

\section{Associated ocular damage}

Crystalline lens expulsion, which occurred in 11 eyes (5 in the LP group and 6 in the NLP group), was a poor prognostic factor for visual outcome $(p=0.0003)$. However, results showed that phakia, aphakia, and pseudophakia were not significant predictive factors for visual outcome.

A history of penetrating keratoplasty (PK) was found in $4(30.8 \%)$ of 13 eyes in the NLP group (30.8\%) and in 3 (6.5\%) eyes in the LP group. A past history of PK was a statistically significant poor prognostic factor for visual outcome $(p=0.017)$.

Both RD and VH were statistically significant poor prognostic factors for visual outcome $(p=0.0001$ and $p=0.044$, respectively). Pars plana vitrectomy (PPV) was performed in $11 \mathrm{RD}$ cases. Retinal re-attachment with a good visual outcome was found in 8 cases (LP group), while 3 cases (NLP group) failed to obtain a good visual outcome primarily due to a severely torn retina. PPV was additionally performed as the primary procedure in 22 cases that presented with $\mathrm{VH}$. Of these, 3 cases (NLP group) failed to gain a good visual outcome, while 19 cases (LP group) did achieve a good visual outcome after the procedure. 
Our results also showed that there were no significant predictive factors or any statistically significant differences between the two groups in this study for other associated ocular damage, such as choroidal hemorrhage and hyphema. In addition, we did not find a single case of traumatic or postoperative endophthalmitis in this study.

\section{PPV}

PPV was performed as the primary operation in 29 (49.2\%) cases. The most common indications were VH (22 [75.9\%] of 29 eyes) and RD (11 [37.9\%] of 29 eyes), with 26 (56.5\%) patients undergoing the procedure in the LP group and $3(23.0 \%)$ patients in the NLP group. Eyes that underwent PPV were significantly more likely to achieve a final vision of LP or better as compared to those that did not $(p=0.033)$. Furthermore, in the eyes that achieved a final VA of LP or better, those that underwent PPV were found to have slightly better visual outcomes (0.81 logMAR) versus those that did not undergo the procedure (1.1 logMAR). In 2 cases where the globes were severely disorganized in addition to a fear of the subsequent occurrence of sympathetic ophthalmia, enucleation was performed as the primary procedure.

\section{Visual acuity}

Poor VA at the first visit $(p=0.00001)$, a ruptured globe $(p=0.026)$, history of PK $(p=0.017)$, zone III injuries $(p=0.04), \mathrm{RD}(p=0.0001), \mathrm{VH}(p=0.044)$, and expulsion of the crystalline lens $(p=0.0003)$ were all determined to be poor prognostic factors. Patients with a wound that was smaller than $5 \mathrm{~mm}$ had a significantly better VA than those groups that had wounds that were larger than $5 \mathrm{~mm}$ $(p=0.0078)$. Eyes that were first treated with PPV were significantly more likely to achieve a final vision of LP or better $(p=0.033)$. Figure 3 shows the correlation between the initial and final VA. As seen in this figure, even if the initial VA was poor, there was variation in the final VA.

\section{Discussion and conclusion}

This study evaluated the visual outcomes after open-globe injuries in Japanese patients and tried to identify the possible risk factors and the prognostic factors responsible for the final visual outcomes. To the best of our knowledge, this is the first study that has examined the prognostic factors of open-globe injuries in the Japanese population.

The mean age of our study populations was $56.7 \pm$ 21.8 years in the LP group and $62.3 \pm 21.7$ years in the NLP group. These values are higher than those that have been reported in other studies [11-14]. Additionally, the mean age of the work-related trauma group was $51.3 \pm 18.1$ years while that for the falls group was $61.1 \pm 8.8$ years. This variability may be due to inter-population differences in the culture, lifestyle, mean lifespan, occupation, and socioeconomic status. Unlike other studies that have reported finding a prevalence of children with eye traumas [11-14], we only encountered 1 case of a patient who was younger than 16 years of age.

The male predominance (male:female $=2: 1$ ) observed in our current study is in agreement with the results of several previous studies [12, 14-17]. As previously speculated, this most likely indicates that males probably have a higher risk of being exposed to dangerous situations in the workplace or during outdoor activities, as well during gender-based behavior [16].

Occupational injuries predominate in older age groups, with work-related trauma (27 [45.76\%] eyes) followed by falls at home (19 [32.2\%] eyes) the most common causes of trauma that result in open-globe injuries. In the relatively younger age groups, the trauma was related to sports injuries (6 [10.2\%] eyes).

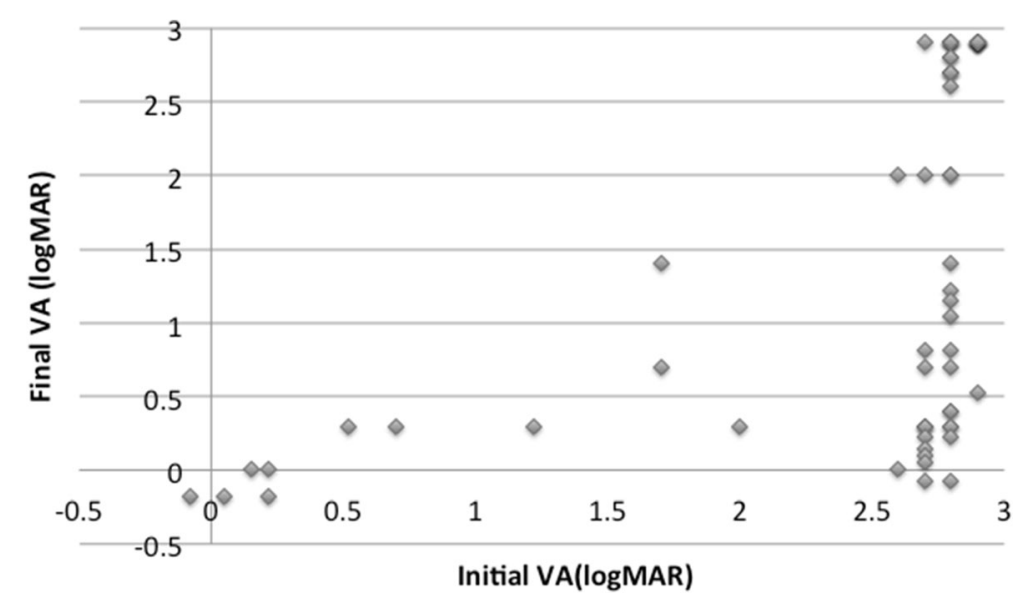

Fig. 3 Correlation between the initial and final VA. Even when the initial VA was poor, there was variation in the final VA 
In line with our results, the previous literature has also reported that the most frequently associated cause of trauma was occupational injury [11, 13, 18, 19]. Other studies have confirmed that the majority of open-globe injuries occur in the home, ranging from 38 to $71 \%$ of the cases [20, 21]. However, Tok et al. [22] and El-Sebaity et al. [5] reported that injuries at home were less prevalent than those outside the home in pediatric cases. However, work-related trauma remains an important cause of avoidable and predominantly monocular visual morbidity, due to the fact that the majority of injuries are the result of not following proper safety precautions. Although the use of safety precautions had no effect on the final visual acuity, safety precautions are advised for all practical purposes as a means of preventing injuries, ocular or otherwise [18].

Although one of the important causes of open-globe is related to car accidents, our current study found that only $2(3.4 \%)$ cases were due to an automobile accident. Thevi et al. confirmed that road accidents are the second cause of open-globe injuries $(n=17,32.7 \%)$ [18].

The most frequent mechanism of injury was rupture injury (69.5\%), which was followed by IOFBs (20.3\%) and penetrating injury (10.2\%). All 13 (100\%) eyes in the NLP group presented with a ruptured globe, which was a poor prognostic factor $(p=0.026)$. All cases of IOFB and penetrating injuries were related to the LP group and had a better prognosis than rupture injury.

All 12 of the IOFB cases occurred in the workplace, with 11 cases due to metal origin and 1 case due to concrete. IOFB removal was successful in all cases. A study by Madhusdhan et al. reported that the cases were predominantly penetrating injuries and that the mechanism of injury was not significantly associated with the final visual acuity [11]. Our study confirmed that rupture was a mechanism of injury with a poor prognosis for the visual outcome $(p=0.026)$, which is in agreement with other studies that showed rupture was associated with a lower rate of both visual function and functional success rates than laceration $[12,23]$. Additionally, these studies confirmed that both IOFB (other than metal pellets fired from a $\mathrm{BB}$ gun) and penetrating injuries resulted in better visual results and prognoses [12, 23]. Perforating injuries from explosions and gunshots were not observed in our current cases, as these are rare in the Japanese community.

In our study, patients with wounds that were smaller than $5 \mathrm{~mm}$ had a good prognosis for the visual outcome compared to patients with wounds that were larger than $5 \mathrm{~mm}(p=0.0078)$, which is in accordance with several previous reports $[14,17,18,24,25]$. A larger wound reflects more extensive ocular tissue damage and a higher likelihood of posterior involvement. Additionally, Rofail et al. demonstrated that a laceration larger than $10 \mathrm{~mm}$ had a 14.49-fold risk of attaining a final VA of CF or worse compared with lacerations that were 1 to $5 \mathrm{~mm}$ [14].

Han and $\mathrm{Yu}$ established that a larger wound (>10 $\mathrm{mm})$ was related to a poorer final visual acuity [12]. These findings suggested that the size of the laceration had both therapeutic and prognostic implications, with an increase in the laceration length significantly correlated to a worse visual outcome $(p<0.001)$.

Our results also demonstrated that the zone of the injury was associated with the visual outcome. Wounds involving zone III had significantly poorer visual outcomes versus those involving zones I or II. This result is supported by previous studies, which reported a significant association between the posterior extension of the wound and a worse final VA [3, 11, 12, 18, 26-28]. Madhusudhan et al. reported that subjects with a wound extending posterior to the equator had 20 times the risk of having a final visual acuity less than 3/60 as compared to patients whose wounds were anterior to the recti insertions or restricted to the cornea [11].

Our study showed that a poor VA at the first visit was an important prognostic factor $(p=0.00001)$. A good initial VA was the strongest prognostic factor of a favorable final VA in both the univariate and multivariate analyses, similar to that reported by other numerous studies [4, 11-18, 23-25].

$\mathrm{Han}$ and $\mathrm{Yu}$ performed a multivariate analysis and demonstrated that an initial VA of LP or better resulted in an 18.2-fold chance of attaining visual survival, while CF or better resulted in a 2.81 -fold chance of achieving functional success. This result suggests that a better initial VA reflects milder ocular tissue damage, which ensures a better visual outcome. In contrast, an initial VA of NLP suggests serious ocular tissue destruction, particularly of the retina and optic nerve [12].

Many previous studies have reported finding a significant correlation between the lenticular involvement and the visual outcome $[12,15,23,24,29]$. In our study, crystalline lens expulsion was observed in 11 eyes (5 in the LP group and 6 in the NLP group) and this group had a significantly poor prognosis for the visual outcome $(p=0.0003)$. In contrast, phakia, aphakia, and pseudophakia were not significant predictive factors for the visual outcome. Thus, expulsion of the crystalline lens can be used to document the degree or extensiveness of the injury and determine if it will affect other important structures in the eye, thereby leading to a worse visual outcome.

Our study found a history of PK in 4 (30.8\%) of the 13 eyes in the NLP group and in $3(6.5 \%)$ of the cases in the LP group. To the best of our knowledge, this is the first study to clarify that PK is a poor prognostic factor for open-globe injuries, and that there is a statistically significant association with the visual outcome $(p=0.017)$. 
As previously discussed, we evaluated 12 IOFB cases that all occurred in the workplace. In all cases, the IOFB removal was successful, with 11 cases due to a metal origin and 1 cased due to concrete. All of these IOFB cases belonged to the LP group, and they did not show that the group had a poor predictive effect on the visual outcome. This may be due to the location of the IOFB, as only 1 case was present at the posterior pole nasal to the optic disc, while all of the others were distributed in the anterior chamber (3 cases), vitreous ( 2 cases), and peripheral retina (6 cases). Although we did not find the IOFB to be a significant predictive factor, its prevalence as the second major mechanism of injury suggest that it should carefully evaluated, especially if it is a preventable cause. Though there are mandatory regulations that have been designed to reduce the incidence of eye trauma, such as the use of protective glasses in the workplace, many people simply ignore these precautions. Thus, there needs to be a widespread increased public awareness about eye injuries, IOFB complications, and measures that can be taken in order to prevent eye trauma, especially among those workers who are exposed to such dangers during their normal workdays.

Our current study showed that both $\mathrm{RD}$ and $\mathrm{VH}$ were significantly poor prognostic factors for visual outcomes. These findings are in agreement with previous studies that also reported RD to be a poor prognostic factor for visual outcome $[3,12,15,30,31]$. Additionally, other previous studies have found $\mathrm{VH}$ to be a poor predictive factor for visual outcome [15, 23, 24, 29-31]. However, there were no cases of endophthalmitis in our current study, which may be due to the early closure of the wound and prompt initiation of antibiotics that was performed in all of our cases.

One of the challenges in the treatment of open-globe injuries is identifying the optimal timing for the ultimate reconstruction, namely vitrectomy. While it is clear that suture-closure of the wound for open-globe injuries should be performed as soon as possible, it is less clear whether vitrectomy should be performed during the same surgical session (primary comprehensive reconstruction) or deferred until a later time (staged approach) [32].

In this study, we concluded that eyes that underwent PPV as the primary procedure were significantly more likely to achieve a final vision of LP or better versus those that did not undergo the procedure $(p=0.033)$. PPV was the primary operation used in 29 (49.2\%) of the cases, with 26 (89.7\%) exhibiting a good visual outcome (LP group) and 3 (10.4\%) failing to achieve a gain in their vision (NLP group). This is in agreement with previous studies that have demonstrated the efficacy of vitreoretinal surgery for treating open-globe injuries [12, 33-35]. In a retrospective, matched cohort study,
De Juan et al. found no benefit of vitrectomy in the management of penetrating ocular injury [29]. It should be noted, however, that this is a relatively old study that was performed in 1983, which was well before the marked improvement of the PPV techniques and instrumentation that are currently available.

Another important feature in our current versus the previous studies is that we evaluated the number of open-globe injuries over a period of more than 5 years. The number of these injuries was less than one patient per month (59 cases/66 months), which indicates an awareness by the Japanese population with regard to the use of protective measures for preventing open-globe injuries.

The limitation of our study is related to insufficient documentation, especially with regard to the presence or absence of a relative afferent papillary defect (RAPD).

In conclusion, improvements in our knowledge of the pathophysiology of eye trauma and its prognostic factors, as well as advances in diagnostic and therapeutic techniques, have greatly improved the success rates for managing open-globe injuries. A better understanding of these prognostic factors may help provide our patients with better and more realistic expectations of their final VA. This study demonstrated that a poor VA at the first visit, a ruptured globe, zone III injuries, PK, RD, VH, and expulsion of the crystalline lens are considered to be poor prognostic factors for open-globe injuries. Patients with a wound smaller than $5 \mathrm{~mm}$ had a significantly better VA than the other groups with wounds larger than $5 \mathrm{~mm}$. When patients with open-globe injuries had posterior segment involvement, PPV proved to be a good prognostic factor.

\section{Acknowledgements \\ Not applicable. \\ We confirm that we have given due consideration to the protection of intellectual property associated with this work and that there are no impediments to publication, including the timing of publication, with respect to intellectual property. In so doing we confirm that we have followed the regulations of our institutions concerning intellectual property. We understand that the Corresponding Author is the sole contact for the Editorial process (including Editorial Manager and direct communications with the office). He is responsible for communicating with the other authors about progress, submissions of revisions and final approval of proofs. We confirm that we have provided a current, correct email address which is accessible by the Corresponding Author and which has been configured to accept email from (yasserhelmy@nagasaki-u.ac.jp) Corresponding Author signature on behave of all Authors: Yasser Helmy Mohamed.}

\section{Funding}

We wish to confirm that we have no funding support to report. We wish also to confirm that all authors have no financial disclosures in medicine to report ("No financial disclosures") associated with this publication and there has been no significant financial support for this work that could have influenced its outcome.

\section{Availability of data and materials}

The datasets used and/or analysed during the current study available from the corresponding author on reasonable request. 


\section{Authors' contributions}

All authors except YM carried out the surgical operations to reconstruct globes after trauma. YM and AF participated in the sequence alignment and drafted the manuscript. AF and TK participated in the design of the study and performed the statistical analysis. All authors conceived of the study, and participated in its design and coordination and helped to draft the manuscript. All authors read and approved the final manuscript.

\section{Ethics approval and consent to participate}

This study was approved by the Institutional Review Board (IRB) of the Nagasaki University.

Hospital and adhered to the tenets of the Declaration of Helsinki.

\section{Consent for publication}

Written consent was obtained from all the participants. Manuscript does not contain any individual personal data or photographs.

\section{Competing interests}

The authors declare that they have no competing interests.

\section{Publisher's Note}

Springer Nature remains neutral with regard to jurisdictional claims in published maps and institutional affiliations.

\section{Author details}

'Department of Ophthalmology and Visual Sciences, Graduate School of Biomedical Sciences, Nagasaki University, 1-7-1 Sakamoto, Nagasaki, Nagasaki 852-8501, Japan. ${ }^{2}$ Department of Ophthalmology, EL-Minia University Hospital, EL-Minia, Egypt. ${ }^{3}$ Department of Ophthalmology and Visual Sciences, Graduate School of Medicine Kyoto University, Kyoto, Japan.

\section{Received: 5 September 2017 Accepted: 30 May 2018}

\section{Published online: 08 June 2018}

\section{References}

1. Eballe AO, Epee E, Koki G, Bella L, Mvogo CE. Unilateral childhood blindness: a hospital based study in Yaounde, Cameroon. Clin Ophthalmol. 2009;3:461-4.

2. May DR, Kuhn FP, Morris RE, Witherspoon CD, Danis RP, Matthews GP, Mann $L$. The epidemiology of serious eye injuries from the United States eye injury registry. Graefes Arch Clin Exp Ophthalmol. 2000;238(2):153-7.

3. Pieramici DJ, Sternberg P, Jr., Aaberg TM, Sr., Bridges WZ, Jr., Capone A, Jr., Cardillo JA, de Juan E, Jr., Kuhn F, Meredith TA, Mieler WF, Olsen TW, Rubsamen P, Stout T. A system for classifying mechanical injuries of the eye (globe). The Ocular Trauma Classification Group Am J Ophthalmol 1997:123(6):820-831.

4. Negrel AD, Thylefors B. The global impact of eye injuries. Ophthalmic Epidemiol. 1998:5(3):143-69.

5. El-Sebaity DM, Soliman W, Soliman AM, Fathalla AM. Pediatric eye injuries in upper Egypt. Clin Ophthalmol. 2011;5:1417-23.

6. Khatry SK, Lewis AE, Schein OD, Thapa MD, Pradhan EK, Katz J. The epidemiology of ocular trauma in rural Nepal. Br J Ophthalmol. 2004;88(4):456-60.

7. Soylu M, Sizmaz S, Cayli S. Eye injury (ocular trauma) in southern Turkey: epidemiology, ocular survival, and visual outcome. Int Ophthalmol. 2010;30(2):143-8.

8. Onakpoya OH, Adeoye A, Adeoti CO, Ajite K. Epidemiology of ocular trauma among the elderly in a developing country. Ophthalmic Epidemiol. 2010:17(5):315-20

9. Kadappu S, Silveira S, Martin F. Aetiology and outcome of open and closed globe eye injuries in children. Clin Exp Ophthalmol. 2013:41(5):427-34.

10. Heidari $E$, Taheri N. Surgical treatment of severely traumatized eyes with no light perception. Retina. 2010;30(2):294-9.

11. Madhusudhan AL, Evelyn-Tai LM, Zamri N, Adil H, Wan-Hazabbah WH. Open globe injury in Hospital Universiti Sains Malaysia - A 10-year review. Int J Ophthalmol. 2014;7(3):486-90.

12. Han SB, Yu HG. Visual outcome after open globe injury and its predictive factors in Korea. J Trauma. 2010;69(5):E66-72.

13. Yalcin Tok O, Tok L, Eraslan E, Ozkaya D, Ornek F, Bardak Y. Prognostic factors influencing final visual acuity in open globe injuries. J Trauma. 2011;71(6):1794-800
14. Rofail M, Lee GA, O'Rourke P. Prognostic indicators for open globe injury. Clin Exp Ophthalmol. 2006:34(8):783-6.

15. Schmidt GW, Broman AT, Hindman HB, Grant MP. Vision survival after open globe injury predicted by classification and regression tree analysis. Ophthalmology. 2008;115(1):202-9.

16. Rahman I, Maino A, Devadason D, Leatherbarrow B. Open globe injuries: factors predictive of poor outcome. Eye (Lond). 2006;20(12):1336-41.

17. Entezari M, Rabei HM, Badalabadi MM, Mohebbi M. Visual outcome and ocular survival in open-globe injuries. Injury. 2006;37(7):633-7.

18. Thevi T, Mimiwati Z, Reddy SC. Visual outcome in open globe injuries. Nepal J Ophthalmol. 2012:4(2):263-70.

19. Altintas L, Altintas O, Yuksel N, Pirhan D, Ozkan B, Caglar Y. Pattern of open eye injuries in Northwest Turkey: a retrospective study. Ulus Travma Acil Cerrahi Derg. 2011;17(4):334-9.

20. Framme C, Roider J. Epidemiology of open globe injuries. Klin Monatsbl Augenheilkd. 1999;215(5):287-93.

21. Falcao M, Camisa E, Falcao-Reis F. Characteristics of open-globe injuries in northwestern Portugal. Ophthalmologica. 2010;224(6):389-94.

22. Tok O, Tok L, Ozkaya D, Eraslan E, Ornek F, Bardak Y. Epidemiological characteristics and visual outcome after open globe injuries in children. J AAPOS. 2011;15(6):556-61.

23. Pieramici DJ, MacCumber MW, Humayun MU, Marsh MJ, de Juan E. Open-globe injury. Update on types of injuries and visual results. Ophthalmology. 1996;103(11):1798-803.

24. Sternberg P Jr, de Juan E Jr, Michels RG, Auer C. Multivariate analysis of prognostic factors in penetrating ocular injuries. Am J Ophthalmol. 1984;98(4):467-72.

25. Gilbert CM, Soong HK, Hirst LW. A two-year prospective study of penetrating ocular trauma at the Wilmer Ophthalmological institute. Ann Ophthalmol. 1987;19(3):104-6.

26. Soni NG, Bauza AM, Son JH, Langer PD, Zarbin MA, Bhagat N. Open globe ocular trauma: functional outcome of eyes with no light perception at initial presentation. Retina. 2013:33(2):380-6.

27. Knyazer B, Levy J, Rosen S, Belfair N, Klemperer I, Lifshitz T. Prognostic factors in posterior open globe injuries (zone-III injuries). Clin Exp Ophthalmol. 2008;36(9):836-41.

28. Al-Mezaine HS, Osman EA, Kangave D, Abu El-Asrar AM. Prognostic factors after repair of open globe injuries. J Trauma. 2010;69(4):943-7.

29. De Juan E Jr, Sternberg P Jr, Michels RG. Penetrating ocular injuries. Types of injuries and visual results. Ophthalmology. 1983;90(11):1318-22.

30. Brinton GS, Aaberg TM, Reeser FH, Topping TM, Abrams GW. Surgical results in ocular trauma involving the posterior segment. Am J Ophthalmol. 1982;93(3):271-8.

31. Groessl S, Nanda SK, Mieler WF. Assault-related penetrating ocular injury. Am J Ophthalmol. 1993;116(1):26-33.

32. Kuhn F. The timing of reconstruction in severe mechanical trauma. Ophthalmic Res. 2014;51(2):67-72.

33. Sheard RM, Mireskandari K, Ezra E, Sullivan PM. Vitreoretinal surgery after childhood ocular trauma. Eye (Lond). 2007;21(6):793-8.

34. Erakgun T, Egrilmez S. Prognostic factors in vitrectomy for posterior segment intraocular foreign bodies. J Trauma. 2008;64(4):1034-7.

35. Szijarto Z, Gaal V, Kovacs B, Kuhn F. Prognosis of penetrating eye injuries with posterior segment intraocular foreign body. Graefes Arch Clin Exp Ophthalmol. 2008;246(1):161-5.

\section{Ready to submit your research? Choose BMC and benefit from}

- fast, convenient online submission

- thorough peer review by experienced researchers in your field

- rapid publication on acceptance

- support for research data, including large and complex data types

- gold Open Access which fosters wider collaboration and increased citations

- maximum visibility for your research: over $100 \mathrm{M}$ website views per year

\section{At BMC, research is always in progress.}

Learn more biomedcentral.com/submissions 